ISSN:

vol. 1 , no. 1,2020

page. $10-19$

\title{
Struktur dan Nilai Sosial dalam Dongeng Cinderella dan Cerita Putri Arabella: Kajian Sastra Bandingan
}

\author{
Ega Setia Nanda ${ }^{1, *}$ Yenni Hayati ${ }^{1}$ \\ ${ }^{1}$ Universitas Negeri Padang \\ *corresponding author: egananda@ fbs.unp.ac.id
}

\begin{abstract}
Children literature have long been believed to contain values that contribute to shaping the character of the young reader. The children fiction from many countries always offer noble values that can influence the character formation. This study discusses social values in the Cinderella fairy tale (Indonesian version) and the story of Putri Arabella (the Malaysian version). This study used a comparative literature approach to obtain a comprehensive comparison between the fairy tales of Cinderella and Putri Arabela. The data were analyzed using the content analysis method to obtain a sharper and deeper meaning behind the qualitative data in the form of words, phrases, dialogues and narratives. The results of the data analysis found that the two stories both contained social values, the value of compassion, advice to help others, and a sense of responsibility. Besides having similarities, these two stories also contain differences. The differences were found in the characterization and setting of the story. This is because this story originates from two different countries which contain different social conditions.
\end{abstract}

Keywords: narrative structure, social values, children's stories, comparative literature

\begin{abstract}
Abstrak. Karya sastra telah sejak lama diyakini memuat nilai-nilai yang berkontribusi dalam pembentukan karakter pembaca. Dalam beberapa cerita anak dari negara manapun juga selalu menawarkan nilai-nilai yang luhur yang bisa mempengaruhi nilai karakter pembaca muda tersebut. Penelitian ini mendiskusikan nilai-nilai sosial dalam dongeng Cinderella (versi Indonesia) dan cerita Putri Arabella (versi Malaysia). Penelitian ini menggunakan ancangan Sastra Bandingan untuk mendapatkan perbandingan menyeluruh antara dongeng Cinderella dan Putri Arabella. Data dianalisis dengan metode analisis isi untuk mendapatkan pemaknaan yang lebih tajam dan mendalam dibalik data kualitatif yang berwujud kata, frasa, dialog maupun narasi. Hasil analisis data menemukan bahwa kedua cerita tersebut sama-sama mengandung nilai sosial, nilai kasih sayang, tolong menolong, dan rasa tanggung jawab. Di samping memiliki kesamaan, kedua cerita ini juga memuat perbedaan. perbedaan ditemukan berada pada karakterisasi dan penggambaran latar cerita. Hal itu disebabkan karena cerita ini berasal dari dua negara yang berbeda yang memuat kondisi sosial masyarakatnya juga berbeda.
\end{abstract}

Kata Kunci: struktur, nilai sosial, cerita anak, sastra bandingan

\section{Pendahuluan}

Karya sastra merupakan suatu bentuk ekspresi seorang penulis yang bernilai seni yang dituangkan melalui medium bahasa, baik dalam bentuk lisan ataupun tulisan (Dimitrova, 2016). Dalam karya sastra, biasanya juga tercermin beberapa aspek kehidupan masyarakat yang 
disampaikan secara kreatif oleh seorang pengarang (Hayati, 2018). Pengarang dapat menyampaikan semua hasil pemikirannya melalui karya sastra tersebut. Masyarakat dan segala permasalahan yang terjadi, baik dari dalam diri sendiri maupun dari lingkungannya adalah suatu objek yang layak untuk dijadikan hasil penciptaan dalam sebuah karya sastra. Karya sastra sebagai bentuk media, dapat menghubungkan pemikiran pengarang yang disampaikan kepada pembaca (Livingston, 2019).

Karya sastra yang merupakan gambaran dari kehidupan sosial dan budaya masyarakat diciptakan dari hasil imajinasi pengarang, tidak hanya memberikan hiburan kepada pembaca, tetapi juga memberikan ide dalam menyalurkan sebuah pikiran, perasaan serta dapat merubah sudut pandang pembaca (Vana, 2020). Menurut Wellek dan Warren (2019) bahwa istilah sastra sebagai karya "imajinatif" tidak berarti semua harus memakai imaji (citra). Ada beberapa karya sastra yang memang murni menggunakan imajinasi, ada pula yang diciptakan berdasarkan pengamatan dan pengalaman nyata terhadap suatu realita yang terjadi (Dimitrova, 2016). Pada penjabaran di atas, dapat dikatakan bahwa permasalahan dan konflik yang dideskripsikan pengarang dalam karya sastra, dapat memberikan kesadaran bahwa apa yang terjadi dalam karya sastra juga bisa terjadi pula dalam kehidupan nyata.

Karya sastra ditulis tidak hanya untuk dinikmati oleh pembaca remaja dan dewasa, tetapi juga untuk anak-anak atau lazim disebut Sastra Anak (Children Literature). Karya sastra untuk pembaca muda tersebut dapat ditulis oleh penulis belia atau ditulis oleh pengarang yang telah berpengalaman (Hayati, 2014). Karya sastra merupakan media yang efisien untuk mengajarkan anak mengenai segala sesuatu, seperti sains, nilai moral, nilai budi pekerti, dan nilai agama, karena karya sastra ditopang oleh struktur cerita yang membantu anak untuk lebih memahami hal-hal yang terdapat dalam, sains, dan pengajaran nilai moral tersebut (Hayati, 2016). Hal ini menandakan bahwa karya sastra juga penting bagi anak untuk membentuk dirinya.

Sebenarnya, Sastra Anak sudah lama hadir di Indonesia dan dikenal oleh masyarakat luas walaupun saat ini keberadaannya kurang diperhatikan. Sebagaimana yang dinyatakan Hayati (2016) bahwa munculnya Sastra Anak dianggap sebagai perkembangan yang ikut meramaikan khazanah sastra dunia. Selain itu, Sastra Anak merupakan sebuah karya imajinatif yang mana pusat penceritaannya adalah anak-anak itu sendiri. Isi kandungan dalam Sastra Anak berupa pengalaman dan pengetahuan seorang anak yang dapat dijangkau dan dipahami oleh anak-anak. Sastra Anak pada umumnya berisikan cerita yang sederhana dan sering terjadi, ceritanya juga berupa fantasi atau cerita yang bisa saja tidak masuk akal bagi orang dewasa (Goldstein and Russ, 2000).

Cerita dalam karya Sastra Anak harus menarik, agar anak-anak tidak merasa bosan saat membacanya. Ada tiga syarat karya sastra dikatakan sastra anak-anak, yaitu (1) tokoh utama dalam cerita adalah anak-anak, (2) hubungan ide, tema, dan bahasa berbentuk sederhana, dan tidak lupa pula berisi ajaran moral (Hayati, 2016). Syarat lain dari Sastra Anak adalah bahwa cerita yang disampaikan harus mampu memberikan informasi pengalaman hidup dan pengajaran moral dalam menjalankan kehidupan. Sastra Anak senantiasa memuat nilai yang akan mempengaruhi anak, nilai itu biasanya berkaitan dengan sosial, budaya, sejarah, dan ideologi (Hayati, 2016).

Dalam kebanyakan karya sastra terdapat nilai-nilai yang dianggap memengaruhi pembentukan karakter pembacanya. Salah satunya adalah nilai sosial. Nilai sosial mengandung prinsip-prinsip bagaimana seseorang bertingkah laku, baik untuk dirinya sendiri atau dengan lingkungan sekitar. Dalam kehidupan bermasyarakat, biasanya terdapat nilai-nilai yang akan 
dijadikan pedoman hidup masyarakat yang mana juga hadir dalam narasi tulisan fiksi, karena karya sastra merupakan cerminan kehidupan masyarakat. Sebagai contoh, negara-negara di semenanjung Melayu sering memasukkan nilai-nilai sosial ke dalam cerita-cerita mereka, terutama dengan target pembaca muda (Asmawati, Hayati, Pertiwi \& Adek, 2020). Oleh karena fenomena tersebut, makalah ini bertujuan untuk mendiskusikan nilai-nilai sosial yang terdapat dalam Sastra Anak di negara melayu yakni Indonesia dan Malaysia. Adapun karya yang menjadi sumber data yakni dongeng Cinderella dan cerita Putri Arabella.

Dongeng Cinderella dan cerita Putri Arabella saling memiliki keterkaitan dan persamaan, baik dari unsur intrinsik dan ekstrinsik. Kedua cerita mengisahkan penderitaan seorang gadis perempuan yang hidup bersama dengan ibu tiri dan saudara tirinya yang jahat, namun di akhir cerita, keduanya menikah dengan figur pangeran dan hidup bahagia. Persamaan juga ditemukan dalam penggambaran perwatakan tokoh dan konflik yang terjadi. Walaupun begitu, keduanya disajikan dalam dua bahasa yang berbeda yakni Bahasa Indonesia dan Melayu.

\section{Metode}

Data dianalisis dengan beberapa tahapan diantaranya pembacaan secara mendalam, kodifikasi, klasifikasi, deskripsi dan penarikan kesimpulan. Dengan menggabungkan perspektif French dan American Comparative Literature (Remak, 1990; Ziolkowski \& Clements, 1980), parameter yang digunakan sebagai acuan bandingan untuk kedua karya tersebut adalah unsur intrinsik dan nilai sosial. Berdasarkan tujuan, penelitian ini mencoba untuk memperoleh interpretasi dan pemahaman yang mendalam tentang nilai, pemikiran, perilaku, gagasan, dan konteks sosial produk budaya yaitu dongeng. Hal-hal di atas berusaha didapatkan melalui data bersumber dari tuturan dan narasi dalam karya sastra. Atas dua dasar tersebut, maka penelitian ini bersifat kualitatif (Taylor, Bogdan \& DeVault, 2016). Selain itu, penelitian ini juga merupakan kajian kesusastraan yang bermaksud untuk membandingkan dua karya sastra dari dua negara yang berbeda atau lazim disebut sastra bandingan (Damono, 2009).

Dua cerita berjudul Cinderella (Indonesia) dan Putri Arabella (Malaysia) dipilih sebagai objek yang dipertandingkan. Meski berasal dari dua negara dan bahasa yang berbeda (Indonesia dan Malaysia), keduanya masih dalam kategori 'serumpun'. Kedekatan geografis dan historis antara keduanya diyakini menjadi faktor krusial yang memengaruhi cakupan tafsir kedua karya sastra tersebut.

Data dianalisis dengan beberapa tahapan diantaranya pembacaan secara mendalam, kodifikasi, klasifikasi, deskripsi dan penarikan kesimpulan. Dengan menggabungkan perspektif French dan American Comparative Literature (Remak, 1990; Ziolkowski \& Clements, 1980), parameter yang digunakan sebagai acuan bandingan untuk kedua karya tersebut adalah unsur intrinsik dan nilai sosial.

\section{Hasil dan Pembahasan}

\section{Analisis Struktur Dongeng Cinderella dan Cerita Putri Arabella}

\section{1) Tokoh dan Penokohan}

Tokoh dan penokohan adalah unsur penting yang digunakan penulis dalam menulis cerita karena dengan adanya tokoh dan penokohan penulis dapat menggambarkan permasalahan yang terjadi di dalam cerita tersebut. Biasanya pemilihan nama tokoh dapat mewakilkan karakter 
tokoh dan mengetahui asal dari cerita tersebut. Untuk mengetahui permasalahan yang terjadi di dalam dongeng Cinderella dan cerita Putri Arabella dilakukan analisis tokoh dan penokohan.

Cinderella merupakan putri kerajaan yang tinggal bersama dengan ibu dan saudara tirinya, yang dikarenakan ibu dan ayahnya telah meninggal. Kejahatan yang dilakukan oleh ibu dan kakak tirinya membuat dia tidak banyak melakukan hal yang dia inginkan, disebabkan rasa sayangnya pada sang ayah maka Cinderella harus mengikuti semua perintah dari ibu dan kakak tirinya. Dalam cerita ini Cinderella digambarkan dengan seorang yang penyabar, yang mau melakukan apapun untuk ibu dan saudara tirinya, berikut terlihat pada kutipan di bawah.

Namun Cinderella begitu sabar menghadapi semua ini, dia berfikir bahwa ayahnya sangat menyanyangi ibu tiri dan saudara tirinya. Maka Cinderella juga harus menyanyangi ibu tiri dan saudara tirinya sebagaimana ayah Cinderella menyanyangi mereka (Nursalamah. 2019:2).

Setelah ibu tirinya dan saudaranya pergi ke pesta dansa, Cinderella mengerjakan pekerjaan rumah itu dan menangis bersedih atas semua penderitaannya selama ini setelah ayahnya menikah lagi (Nursalamah. 2019:3).

Cinderella hanya bisa mengintip dari dalam, ia berdoa supaya kebaikan pangeran dapat membawa Cinderella keluar dan mencoba sepatu itu (Nursalamah. 2019:11).

Dari kutipan di atas terlihat gambaran tokoh Cinderella yang baik hati, sabar, penyayang dan penurut. Bagaimanapun perlakuan ibu dan saudara tirinya dia tetap baik tanpa ada dendam sedikitpun, meski perlakuan mereka sering membuat Cinderella bersedih. Dengan adanya penokohan Cinderella yang ditulis oleh penulis dalam dongeng Cinderella memperlihatkan bahwa seorang putri harus memiliki sikap baik agar disayangi oleh rakyatnya, dan penulis juga ingin mengatakan dalam cerita seperti apapun seseorang jahat kepada kita, maka kita tidak seharusnya membalas dengan kejahatan juga, kita harus sabar menerima perlakuan orang lain tersebut dan tetap memberikan kebaikan tanpa imbalan.

Cerita Putri Arabella berasal dari Malaysia dimana pengarang menggambarkan tokoh Putri Arabella sebagai seorang yang bersifat baik, penyabar, dan patuh sama halnya dengan dongeng Cinderella. Putri Arabella mau melakukan apapun yang diperintahkan oleh bunda tirinya dan kedua kakak tirinya, tanpa mau melawan atau menceritakan pada ayahnya. Putri Arabella tidak pernah ingin membalas dendam dia hanya menerima apa yang terjadi di hidupnya, seperti dalam kutipan di bawah

Putri arabella ingin sahaja mengadu nasibnya kepada ayahandanya. Akan tetapi, apabila mengenangkan ungutan daripada bonda dan kakak-kakak tirinya yang ingin mencederakan dua ekor arnab kesayangannya, dia berasa takut dan hasratnya terpendam begitu saja. (Nadzri, 2013:5)

Tidak hanya Cinderella dan Putri Arabella, seorang pangeran juga digambarkan baik hati, sabar dan penyayang. Pada dasarnya dalam dunia kerajaan seorang pangeran memang harus memiliki sifat baik hati, sabar, dan menepati janji terhadap siapa saja karena pangeran tentunya menjadi pedoman dan cerminan bagi rakyat dalam berperilaku. Dari cerita terlihat bagaimana baik dan sopan sang Pangeran bersikap dan dia pun menepati janjinya akan menikahkan perempuan yang memiliki satu kaca yang sama dengan yang dia punya, sekalipun dia mengetahui bahwa perempuan itu pembantu. Berikut kutipannya.

"Siapakah gadis yang tadi itu nyonya? Saya pikir dia berhak memcoba sepatu kaca ini" (Nursalamah, 2019:10) 
Pangeran terkejut melihatnya, namun Pangeran begitu senang karena ia mendapatkan apa yang diinginkan. Pangeran pun melamar Cinderella tepat paida saat itu, ia meminta Cinderella untuk menikah dengannya. (Nursalamah, 2019:10)

Dalam cerita Putri Arabella juga terdapat tokoh pangeran yaitu Putera Arjuna, seorang putra raja yang memiliki sifat baik hati. Dia menolong Putri Arabella yang tersesat di hutan dan membawanya ke istana untuk diberi makan. Melihat kecantikan Putri Arabella, sang Putera Arjuna pun menikahi Putri Arabella sehingga hidup Putri Arabella menjadi bahagia. Berikut terlihat pada kutipan di bawah ini

Lalu, baginda mempersilakan Putri Arabella mengikutinya pulang ke istanannya di negara Pawanadewa (Nadzri, 2013:20).

Dalam sebuah cerita, tokoh tidak hanya memiliki sifat baik tetapi juga ada yang jahat. Karakter jahat berfungsi untuk memainkan emosi pembaca, dan membuat cerita tersebut semakin menarik. Begitu juga dalam dongeng Cinderella adanya tokoh jahat yang terdapat pada ibu tirinya dan saudara tirinya, terlihat pada kutipan di bawah ini.

Cinderella mengetahui undangan tersebut namun ibu tirinya melarangnya untuk mengikuti pesta dansa itu. Ciderella malah mendapatkan pekerjaan rumah yang sangat banyak dari ibu tirinya, hal ini adalah kesengajaan supaya Cinderella tidak bisa mengikuti pesta itu (Nursalamah, 2019:3).

Dengan melotot ibu tirinya melarang keras dan membentak Cinderella untuk masuk ke dalam rumah

"Lancang sekali kau ingin mencoba sepatu ini, cepat bereskan rumah!” (Nursalamah, 2019:10).

Dari kutipan di atas terlihat betapa jahatnya ibu tiri dan saudara tiri Cinderella, bahkan di depan Pangeran dia tetap bersikap jahat tidak peduli bagaimana pandangan orang lain terhadap dirinya. Terlihat bagaimana penulis membuat pembaca memainkan emosi pembaca. Dari penokohan ini dapat terlihat bahwa tidak hanya ada orang baik di dunia ini tapi juga ada yang jahat, yang rela melakukan apapun untuk mendapatkan apa yang dia mau dan membuat bahagi tanpa memperhatikan bagaimana dampak perilakunya terhadap orang lain.

Tidak hanya ibu tiri dan saudara tiri Cinderella yang jahat, tapi bunda dan kedua kakak tiri Putri Arabella juga memiliki sifat yang sama. Mereka semena-mena menyuruh orang di rumahnya sendiri tanpa ada rasa malu dan kasihan. Dapat dilihat pada kutipan berikut:

Putri Arabella selalu dipaksa menggantikan tugas dayang menyapu sampah dan membersihkan taman di sekitar istana. Memaksanya membasuh persalinan harisn bonda tiri dan kakakkakaknya. (Nadzri, 2013:3)

Akan tetapi tidak buat bonda tiri Putri Arabella. Dia hanya berpura-pura bersedih. Dia telah merancang untuk menikmati kemewahan yang ditinggalkan oleh Raja Iskandar Shah bersama dua orang anak kandungnya (Nadzri, 2013:11).

Kemudian, Putri Arabella diusir keluar dari istana. Dia dibuang ke dalam hutan belantara. (Nadzri, 2013:12)

Dari tiga kutipan di atas terlihat jelas bagaimana jahat dan kejinya perlakuan bunda dan kakak tirinya, bahkan seenaknya mengusir Putri Arabella dari istana dan mengambil semua harta yang ditinggalkan oleh ayahanda Putri Arabella. Dari kedua cerita ini menjelaskan pada 
pembaca bahwa ibu tiri dan saudara tiri itu memiliki sifat yang jahat, penulis secara tidak langsung membuat pembaca membenci akan adanya ibu tiri dan saudara tiri.

\section{2) Latar}

Latar merupakan tempat terjadinya suatu cerita, latar juga mendukung jalanya sebuah cerita tersebut. Latar juga menjadi sebab terjadinya peristiwa-peristiwa tersebut ada dalam cerita. Latar tempat yang ada pada cerita adalah di rumah Cinderella dan di kerajaan. Berikut di bawah ini kutipannya:

Cinderella mengerjakan pekerjaan rumah itu dan menangis bersedih atas semua penderitaannya selama ini setelah ayahnya menikah lagi. (Nursalamah. 2019:3)

Cinderella mendengar suara tamu dari luar, hingga pada akhirnya ia membukakan pintu. (Nursalamah. 2019:7)

Setelah beberapa waktu, Cinderella sampai di kerajaan. Banyak mata yang memandang kagum kehadiran Cinderella (Nursalamah: 2019:5).

Dari kutipan satu dan dua terlihat latar tempat terjadinya peristiwa adalah di rumah Cinderella yang merupakan tempat Cinderella diperlakukan seenaknya oleh ibu tiri dan saudara tirinya. Dalam kutipan ketiga adanya latar tempat kerajaan tempat Cinderella bertemu Pangeran dengan gaun yang sangat cantik bagaikan seorang putri kerajaan hingga membuat Pangeran jatuh hati padanya.

Pada zaman dahulu, daam sebuah negara yang bernama Indrapura (Nadzri, 2013:1).

Setelah berhari-hari sesat dan berjalan di dalam hutan, Putri Arabella berasa sangat keletihan. (Nadzri, 2013:13).

Setelah sampai di istana Pawanada, Putera Arjuna disamput oleh ayahaandanya (Nadzri, 2013:21).

Ketiga kutipan tersebut adalah latar tempat terjadinya peristiwa-peristiwa dalam cerita Putri Arabella, pada kutipan pertama adalah negara tempat tinggal Putri Arabella yang ayahanda nya sebagai raja. Pada kutipan kedua merupakan hutan di mana Putri Arabella dibuang oleh bunda tiri dan kakak tirinya, dia berusaha mencari jalan keluar dari hutan tapi tak juga ketemu sampai akhirnya bertemu Putera Arjuna. Kutipan ketiga merupakan tempat tinggal Putera Arjuna dan ayahanda nya raja di sana, dan di istana Pawanadewalah Putri Arabella hidup bahagia dengan Putera Arjuna.

Pada suatu malam sebelum ibu tiri dan saudara tiri Cinderella berangkat, ibu berpesan pada Cinderella "semua pekerjaan ini harus selesai sebelum aku sampai di rumah". (Nursalamah, 2019:3)

Keesokan harinya ia sudah bangun pagi dan menemukan ibu tiri dan saudaranya tergeletak di ruang tamu. (Nursalamah, 2019:7)

Tidak hanya latar tempat, dalam cerita juga ada latar waktu, yang menunjukkan kapan peristiwa itu terjadi. Dari kutipan di atas terlihat latar waktu dalam dongeng Cinderella yaitu malam hari saat ibu tirinya menyuruhnya menyelesaikan pekerjaan rumah dan pagi hari ketika Pangeran dan pengawalnya datang mencari pemilik sepatu kaca. 
Pada suatu malam, setelah usai merasmikan majlis kesyukuran, tiba-tiba Raja Iskandar Ahtah telah jatuh gering. (Nadzri, 2013: 8)

Namun, setelah hari berganti hari, minggu berganti minggu, dan bulan berganti bulan, penyakit Raja Iskandar Shah tidak juga sembuh. (Nadzri, 2013:9)

Genap sepurnama maka berkahwinlah Putri Arabella dengan Putera Arjuna. Majlis sambut dengan meriah dan penuh dengan adat istiadat diraja. (Nadzri, 2013:23)

Kutipan di atas menjelaskan latar waktu yang terjadi pada cerita Putri Arabella, di mana adanya latar waktu malam yang dijelaskan pingsannya ayahanda Putri Arabella. Kemudian latar waktu dilanjutkan dengan pergantian hari, minggu, bahkan bulan, serta drai kutipan dijelaskan waktu mengenai Putri Arabella yang menikah dengan Putera Arjuna.

\section{3) Alur}

Selain tokoh dan penokohan serta latar, untuk berjalannya suatu cerita maka juga diperlukan alur, yang bertujuan untuk melihat saling keterkaitan antara satu cerita ke cerita lainnya, dan melihat sebab akibat dari cerita tersebut. Begitu juga pada dongeng Cinderella memiliki alur untuk membuat cerita lebih padu, alur yang digunakan penulis adalah laur maju, yang memperlihatkan urutan peristiwa secara terstruktur dari awal sampai akhir cerita. Berikut kutipannya:

Terdapat seorang gadis cantik piatu yang hidup bersama ayahnya yang begitu kaya. Mereka hidup bahagia walaupun terdapat satu anggota keluarga yang kurang di dalamnya yaitu ibu dari Cinderella yang telah meninggal dunia. (Nursalamah: 2019:1)

Sungguh memilukan, tidak lama setelah menikah ayah Cinderella meninggal dunia karena sakit. Bertambah sengsara hidup Cinderella setelah ayahnya meninggal. Semakin leluasa sang ibu tiri dan saudara tirinya untuk bertindak sewenang-wenang terhadap Cinderella. (Nursalamah 2019:2)

Akhirnya Cinderella dapat pergi dari rumah penuh kesengsaraan itu. Ia pun pergi ke kerajaan dengan Pangeran dan melaksanakan pernikahan di sana. (Nursalamah: 2019:12)

Dari ketiga kutipan di atas terlihat bagaimana jalan cerita dongeng Cinderella, yang berurutan dari awal sampai akhir. Cerita yang dimulai dengan kehidupannya bersama ayahnya yang tidak tega melihat Cinderella sendiri di rumah disebabkan ayahnya sering pergi bekerja, sehingga ia menikah lagi agar istrinya dapat merawat Cinderella. Namun setelah ayahnya Cinderella meninggal, Cinderella semakin menderita karena perlakuan ibu tiri dan saudara tirinya. Sampai akhirnya dengan kesabaran Cinderella dapat menikah dan hidup bahagia bersama Pangeran.

Pada zaman dahulu, dalam sebuah Negara yang bernama Indrapura, tinggallah seorang sultan yang bernama sultan iskandar shah bersama isteri dan tiga orang puterinya. (Nadzri. 2013:1)

Lalu, setelah selesai upacara pengebumian raja iskandar shah, bonda tiri Putri Arabella telah menabalkan dirinya sebagai raja yang baharu. Kemudian Putri Arabella diusir keluar dari istana. (Nadzri, 2013:11-12)

Hilanglah kesedihan dan kesengsaraan yang selama ini ditanggung oleh Putri Arabella. Tidak disangka nasibnya yang buruh telah berubah menjadi begitu indah dan bahagia. (Nadzri, 2013: 24) 
Pada cerita Putri Arabella juga didapatkan alur maju, terlihat pada kutipan di atas yang dari awal diceritakan tentang sebuah kerajaan yang hidup satu keluarga, dalam keluarga tersebut adanya perlakuan tidak adil terhadap Putri Arabella oleh bunda dan kakak tirinya. Setelah ayahanda Putri Arabella meninggal, bunda tirinya mengambil harta dan menjadi raja di kerajaan tersebut dan mengusir Putri Arabella. Walaupun begitu Putri Arabella tidak menyerah sampai akhirnya bertemu seorang putra raja yang menolongnya dan menikahinya dengannya sehingga mengubah kehidupannya menjadi bahagia.

\section{Analisis Nilai Sosial Dongeng Cinderella dan Cerita Putri Arabella}

Nilai sosial adalah nilai yang terbentuk oleh tingkah laku dari suatu masyarakat, yang mendapatkan nilai baik dan buruk sesamanya, semuanya dibentuk karena pertimbangan yang ada dari apa yang mereka lakukan. Tidak hanya kenyataan di dalam masyarakat tapi nilai sosial ini juga ada dalam karya sastra, karena karya sastra juga terbentuk dengan adanya masyarakat sekitar. Dalam dongeng Cinderella juga didapatkan nilai sosial yang membentuk karakter dari tokoh tersebut, nilai sosial yang didapatkan ada berupa nilai kasih sayang, tanggung jawab, dan tolong menolong. Hal tersebut tercermin dalam kutipan berikut:

Karena tidak tega melihat Cinderella sering sendirian di rumah, ayahnya pun memutuskan untuk menikah lagi dengan seorang janda yang memiliki 2 anak perempuan. (Nursalamah 2019:1)

Dari kutipan di atas tersebut terlihat betapa sayangnya sang ayah pada Cinderella, dengan adanya rasa kasih sayang seorang ayah maka ayahnya tidak ingin anaknya merasa kesepian dengan sering di rumah sendiri, dia pun menikah dengan janda untuk mencarikan teman dan orang yang menjaga Cinderella. Sebagaimana pendapat Asri, Hayati, \& Adek (2020) mengatakan cinta merupakan sebuah aksi/kegiatan aktif yang dilakukan manusia terhadap objek lain, berupa pengorbanan diri, empati, perhatian, membantu, menuruti perkataan, mengikuti, patuh, dan mau melakukan apapun yang diinginkan objek tersebut.

Dia senantiasa ingat bahawa Rasulullah Saw ada bersabda: "siapa yang tidak mengasihi, maka dia tidak akan dikasihi" (Mustafaqun Alaih, dalam Arabella, 2013:6)

Kutipan ini didapatkan pada cerita Putri Arabella yang menganjurkan pembacanya untuk memiliki sifat kasih sayang antara sesama. Bagaimanapun orang bersikap, seseorang harus tetap baik dan menyayanginya. Rasa kasih sayang ini tidak hanya di dunia nyata atau karya sastra tapi juga semua agama dan ajaran dan hal tersebut tidak hanya untuk sesama manusia tetapi terhadap seluruh yang ada di dunia ini.

Dia berfikir bahwa ayahnya sangat menyayangi ibu tiri dan saudara tirinya. Maka Cinderella juga harus menyayangi ibu tiri dan saudara tirinya sebagaimana ayah Cinderella menyayangi mereka. (Nursalamah, 2019:2)

"Kami diutus sang Pangeran untuk menemui semua gadis yang datang pada pesta dansa tadi malam, kami berharap gadis-gadis uang tadi malam datang dalam pesta dansa berkenaan untuk mencoba sebuah sepatu kaca ini" (Nursalamah, 2019:8)

Nilai yang terdapat dalam kedua kutipan di atas adalah nilai tanggung jawab. Pada kutipan pertama memperlihatkan tanggung jawab Cinderella terhadap ayahnya, yang mana Cinderella harus menyayangi ibu tiri dan saudara tirinya sebagaimana ayahnya menyayangi mereka, itu hanya bentuk tanggung jawab terhadap ayahnya bukan karena benar sayang. Ini terjadi karena perlakuan yang tidak wajar oleh ibu tiri dan saudara tirinya terhadap dirinya di rumah sendiri. 
Pada kutipan kedua melihatkan tanggung jawab seorang pengawal terhadap tugas yang diberikan atasannya. Pengawal tersebut benar-benar mengunjungi setiap gadis yang hadir di pesta dansa semalam untuk mencari gadis yang memiliki ukuran kaki yang sama dengan sepatu kaca yang dibawanya.

Cinderella terkejut melihatnya, peri itu tiba-tiba memberikan bantuan kepada Cinderella berupa tikus-tikus yang membantu pekerjaan rumah Cinderella.(Nursalamah; 2019:4)

Nilai tolong menolong tergambarkan pada kutipan diatas, seorang peri yang memberikan pertolongan pada Cinderella untuk memudahkan pekerjaan sehingga dia dapat pergi ke pesta dansa. Kita sebagai sesama memang seharusnya tolong menolong, karena kita takkan bisa hidup seorang diri tanpa orang lain. Dengan menolong orang maka suatu saat nanti ketika kita berada dalam kesusahan kita juga ditolong oleh orang, itulah kenapa kita harus hidup bermasyarakat.

Lalu, baginda mempersilakan Putri Arabella mengikutinya pulang ke istananya di negara Pawanadewa. Dengan perasaan gembira dan terharu Putri Arabella pun bersetuju lalu naik di belakang kuda yang ditunggangi oleh Putera Arjuna (Nadzri, 2013:20)

Nilai tolong menolong juga didapatkan dalam cerita Putri Arabella, terlihat dari kutipan di atas seorang putra raja menolong Putri Arabella yang terdampar di hutan. Bagaimanapun meski tidak kenal dengan orang tersebut, tapi ketika melihat dia kesusahan kita harus menolongnya, tidak boleh membiarkan begitu saja. Dengan pertolongan yang diberikan Putera Arjuna maka berubahlah kehidupan Putri Arabella, dan hidup bahagia bersama.

Dari pembahasan kedua cerita tersebut memperlihatkan persamaan yang disebabkan oleh banyaknya kemiripan yang dimiliki oleh kedua negara yang menjadi latar pembuatan cerita. Dalam dunia nyata, Indonesia dan Malaysia memiliki persamaan dalam segi budaya dan kemiripan bahasa. Sedangkan perbedaan disebabkan karena interpretasi penulis terhadap cerita yang berbeda yang disebabkan karena latar belakang kehidupan yang juga berbeda.

\section{Simpulan}

Berdasarkan yang apa yang telah dipaparkan tersebut maka dapat disimpulkan bahwa dongeng Cinderella dan cerita Putri Arabella memiliki kesamaan, dari segi tokoh dan penokohan banyak memiliki kemiripan cara pikiran dan perilaku, serta sama-sama memiliki alur maju dan menggunakan latar tempat kerajaan dan waktu terjadinya peristiwa yang juga sama. Pada bagian nilai sosial kedua cerita tersebut juga banyak memiliki nilai kasih sayang, tolong menolong, dan adanya rasa tanggung jawab.

Walaupun berbeda bahasa dan negara tidak menutup kemungkinan adanya persamaan dalam kedua cerita tersebut. Persamaan cerita biasanya disebabkan latar dari sebuah cerita tersebut sama-sama menceritakan tentang kerajaan dan seorang putri yang tersiksa oleh ibu tiri dan saudara tirinya. Dari segi geografis pun cerita juga bisa memiliki kemiripan. Hal itu mungkin saja disebabkan karena adanya migrasi penduduk dari satu tempat ke tempat lain yang membawa kebudayaannya tersebut dalam ini adalah warga Negara Indonesia bermigrasi ke Malaysia atau sebaliknya. Dari data yang ditemukan belum didapatkan cerita manakah yang lebih dulu hadir, dan cerita manakah yang mengalami peminjaman atau penyaduran. 


\section{Referensi}

Asmawati, Hayati, Y., Pertiwi, I. G. D., \& Adek, M. (2020). 'Birds of a Feather Flock Together': The Comparison Between Two Folklores Bawang Merah Bawang Putih and Putri Arabella. Proceedings of the 3rd International Conference on Language, Literature, Culture, and Education (ICOLLITE 2019). Paris, France: Atlantis Press.

Asri, Y., Hayati, Y., \& Adek, M. (2020). Women's perspective on love, loyalty, and the other woman in Indonesian literature. Proceedings of the 3rd International Conference on Language, Literature, Culture, and Education (ICOLLITE 2019). Paris, France: Atlantis Press.

Damono, S. D. (2009). Sastra Bandingan. Jakarta: Editum.

Dimitrova, Z. (2016). Literary worlds and Deleuze: Expression as mimesis and event. Lanham, MD: Lexington Books.

Goldstein, A. B., \& Russ, S. W. (2000). Understanding children's literature and its relationship to fantasy ability and coping. Imagination, Cognition and Personality, 20(2), 105-126.

Hayati, Y. (2014). Representasi ibu dalam sastra anak di Indonesia (Studi Kasus Terhadap Sastra Anak Karya Anak Periode 2000-an). Humanus, 13(1), 45.

. (2016). Representasi Gender dalam Sastra Anak di Indonesia. Padang: FSB UNP.

(2018). Model of planting discipline traits for children in Minangkabau story.

Proceedings of the International Conference on Language, Literature, and Education (ICLLE 2018). Paris, France: Atlantis Press.

Livingston, P. (2019). Literary knowledge: Humanistic inquiry and the philosophy of science. Ithaca, NY: Cornell University Press.

Nadzri, M. N. M. (2013). Putri Arabella. Negeri Sembilan: Universitas Sain Islam Malaysia.

Nursalamah, E. (2019). Dongeng Cinderella. Retrieved from https://id.id.scribd.com/document/37350237/Cinderella

Remak, H. H. H. (1990). Comparative criticism: Cultural and historical roots in the theoretical forest. Neohelicon, 17(1), 161-199.

Taylor, S. J., Bogdan, R., \& DeVault, M. (2016). Introduction to qualitative research methods: A guidebook and resource (4th ed.). New York, NY: John Wiley \& Sons.

Váňa, J. (2020). Theorizing the social through literary fiction: For a new sociology of literature. Cultural Sociology, 14(2), 180-200.

Wellek, R., \& Warren, A. (2018). Theory of literature. Normal, IL: Dalkey Archive Press.

Ziolkowski, T., \& Clements, R. J. (1980). Comparative literature as academic discipline: A statement of principles, Praxis, standards. World Literature Today, 54(1), 175. 